IZA DP No. 8526

Evaluating the Effect of Beauty on Labor Market Outcomes: A Review of the Literature

Xing (Michelle) Liu

Eva Sierminska

October 2014 


\title{
Evaluating the Effect of Beauty on Labor Market Outcomes: A Review of the Literature
}

\author{
Xing (Michelle) Liu \\ University of Arizona \\ Eva Sierminska \\ CEPS/INSTEAD and IZA
}

\section{Discussion Paper No. 8526 \\ October 2014}

\author{
IZA \\ P.O. Box 7240 \\ 53072 Bonn \\ Germany \\ Phone: +49-228-3894-0 \\ Fax: +49-228-3894-180 \\ E-mail: iza@iza.org
}

\begin{abstract}
Any opinions expressed here are those of the author(s) and not those of IZA. Research published in this series may include views on policy, but the institute itself takes no institutional policy positions. The IZA research network is committed to the IZA Guiding Principles of Research Integrity.

The Institute for the Study of Labor (IZA) in Bonn is a local and virtual international research center and a place of communication between science, politics and business. IZA is an independent nonprofit organization supported by Deutsche Post Foundation. The center is associated with the University of Bonn and offers a stimulating research environment through its international network, workshops and conferences, data service, project support, research visits and doctoral program. IZA engages in (i) original and internationally competitive research in all fields of labor economics, (ii) development of policy concepts, and (iii) dissemination of research results and concepts to the interested public.
\end{abstract}

IZA Discussion Papers often represent preliminary work and are circulated to encourage discussion. Citation of such a paper should account for its provisional character. A revised version may be available directly from the author. 


\section{ABSTRACT}

\section{Evaluating the Effect of Beauty on Labor Market Outcomes: A Review of the Literature}

An important underlying determinant of wage discrimination, as well as the gender wage gap is the way the labor market rewards individual physical attractiveness. This article surveys the extensive empirical literature of the effect of physical attractiveness on labor market outcomes. Particular attention is given to the channels through which attractiveness may affect individual labor market outcomes and the way attractiveness affects gender wage differentials. Further research is needed on the effect of attractiveness within occupations in order to provide more evidence on its productivity-enhancing channel of transmission and the effect this has on the gender wage gap.

JEL Classification: J71, J31, J2, J16

Keywords: beauty premium, cross-country, discrimination, gender differentials, human capital model, occupational sorting, physical attractiveness, productivity, stereotypes, wages, wage discrimination

Corresponding author:

Eva Sierminska

CEPS/INSTEAD Research Institute

3 , avenue de la Fonte

L-4364 Esch-sur-Alzette

Luxembourg

E-mail: eva.sierminska@ceps.lu 


\section{Introduction}

The labor economics literature has exhibited a long lasting interest in the examination of wage discrimination. This topic has generated huge amount of research by economists. So far, a large sum of careful empirical studies of wage discrimination based on gender, race, and disabled workers etc. have been produced. In recent years, discrimination in the labor market against a unique group-- those physically unattractive/ attractive--- has brought increasing attention primarily because the number of employment-related discrimination claims based on employees' appearance has continued to increase (Malos, 2007[55]). In July 2001, the city and county of San Francisco released compliance guidelines to prohibit weight and height discrimination in the local labor market. In 2008, the District of Columbia enacted a series of protection measures for employees, by making it illegal to discriminate on the basis of outward appearance for the purpose of recruitment, hiring, or promotion (Hamermesh, 2011[29]) All these local legislations are aimed at protecting those that could find themselves in the physical appearance disadvantaged group. Although, not everyone in the past agreed that these type of efforts should take place (Barrro 1998[3]).

The first economic study on the relationship between appearance and labor market outcomes, which laid a solid foundation for the studies afterward, was provided by Hamermesh and Biddle (1994)[30]. The focal point in this strand of the literature is to determine (1) whether labor market outcomes differentials based on physical appearance exist; and (2) if they exists, what are their potential explanations. Identifying the magnitude of the effect of physical appearance on labor market outcomes (known also as the beauty effect) and the channels through which they work can be critical as policy implications may vary across the various explanations. The effect of appearance may also vary across genders, which, in turn, may affect individual labor market responses (as well as the opportunity in the marriage market), differently. Therefore, studying the beauty effect across genders may help explain the observed gender wage inequality (or gap) to some extent. Further, beauty based labor market outcome premiums (or penalties) may vary in across cultures and across countries, thus the study of country differences may 
shed light on the establishment and development of anti-discrimination laws in other countries.

This article reviews the large literature on the impact of physical attractiveness on labor market outcomes. The focus is on beauty and it is not the goal of the survey to provide an exhaustive review of other physical appearance attributes (such as height and weight, etc.). Section 2 briefly introduces the definition of beauty and the beauty measures. Section 3 summarized the potential explanations of beauty premium/ plainness penalty. Section 4 reviews the empirical models used to estimate the effect of beauty. Section 5 discusses the beauty effect across genders. Section 6 lists the findings of the beauty effects across countries. Section 7 concludes.

\section{What's beauty? Beauty Measure and Alternative Measures}

Seldom have researchers offered a conceptual definition of physical attractiveness primarily because a physical attractive person is hard to define precisely. In Hatfiled \& Sprecher (1986) [37] the authors define physical attractiveness as someone “(...) which represents one's conception of the ideal in appearance; (...) which gives the greatest degree of pleasure to the senses”. By characterizing most previous research, Morrow (1990)[61] proposes a definition of physical attractiveness from an inductive perspective: physical attractiveness is the degree to which one's facial image elicits favorable reaction from another. Although these two definitions of physical attractiveness are fairly consistent, there are few consistent standards of attractiveness across cultures (Hatfield and Sprecher, 1986[37]; Hamermesh and Biddle, 1994[30] Fortunately, it has been shown from previous studies that, within a culture at a point in time, there is tremendous agreement on beauty standards and these standards change fairly slowly over time (Hamermesh and Biddle, 1994[30]) and individuals ten to have similar judgments about what makes a beautiful person (Patzer, 1985[64]). These conclusions made from a psychological and sociological view indicate that attractiveness is at least potentially measureable.

In psychological research, the most common way in which the concept of attractiveness is measured is by asking raters to judge the physical attractiveness of people in portrait 
photographs or to use self-reported appearance ratings. According to the theory mentioned above, physical attractiveness measured in this manner should have high reliability because people within a given culture tend to agree with each other regarding whether a person's facial appearance is attractive or not (Hatfield \& Sprecher, 1986[37]; Umberson \& Hughes, 1987[75], Hamermesh and Biddle, 1994[30]).

${ }^{1}$ In addition to the attractiveness measures induced from evaluating photographs, others have used alternative measures emphasizing other aspects of physical attractiveness. These alternative attractiveness measures include height/ stature (Frieze et al, 1991[24] Loh, 1993[52]; Steckel, 1995[74]; Persico et al., 2004[65]; Deaton \& Arora, 2009 [13]; Loureiro et al., 2012[54]), weight/ obesity/ bmi (Larkin \& Pines, 1979[48]; Haskins \& Ransford, 1999[35]; Register \& Williams, 1990[67]; Frieze et al, 1991[24]; Loh, 1993[52], Averett \& Korenman, 1996[2]; Maranto \& Stenoien, 2000[56]; Cawley, 2004[11]; Loureiro et al., 2012[54]; Caliendo \& Gehrsitz 2014 [9]), appropriateness of dress (Lambert, 1972[46]), hair color (Johnston, 2010[42]), and physical disability (Loureiro et al., 2012[54]). Among all these alternative measures, height and weight are commonly used in economics literature. Some researchers point out that these two measures are less subject to measurement error, do not depend on subjective ratings from observers, and also play a fundamental role in the perception of attractiveness. However from a point of view of validity (or construct validity) these two measures are still not sufficient as the physical attractiveness of a person is more than standard height and weight.

\section{Potential Explanations of Beauty Premium/ Plainness Penalty}

A large body of literature has documented that above average looking workers receive a wage premium while below average looking ones receive a wage penalty. The quandary, then, is why does there exist beauty premium/ plainness penalty and through which channel can physical attractiveness affect earnings? Possible explanations for the channels cited in the literature include: employer discrimination; customer discrimination/ productivity; occupational sorting; and attractiveness affecting

\footnotetext{
1 Although Doorley \& Sierminska (2014)[19] find that interview measured attractiveness can exhibit a personality effect and vary from begining to the end of the interview.
} 
individuals'cognitive/ non-cognitive skills that are important for job performance. While the empirical evidence in support of some of these explanations is relatively thin, the attention they receive in the literature leads us to discuss each of these in turn.

\subsection{Employer discrimination}

There are two conceptually distinct reasons employers might wish to hire more attractive workers. The first is based on a belief that good-looking workers are more productive or more capable even when workers ability is not observed. The second is that employers simple prefer to work with good-looking workers even when they do not have a biased belief about the workers actual ability. The former reason is attributed to an employers' biased belief or stereotype, while the latter is Becker type discrimination.

People respond differently to attractive and unattractive individuals in a work setting. In general, people tend to be favorably biased toward those who are more attractive (Hatfiled and Sprecher, 1986[37]). One may wonder why these attractiveness effects occur. Research by Miller (1988)[57], Dion et al. (1972)[16], and Snyder (1984)[73] provide the most straightforward answer from a psychological point of view. In their studies, they show that one's impression/ belief based on the observation of someone's physical attractiveness affects the way one responds to that person. This type of belief assumes that physically attractive people have more socially pleasing personalities and that they are more likely to be successful in their careers. This biased belief can be particularly important when employers are making hiring decisions during face-to-face interviews. In fact, earlier psychological studies have confirmed the stereotype hypothesis, which predicts that attractive people are more likely to be hired for a variety of jobs (Dipboye et al. 1977[17]; Riggio \& Throckmorton, 1988[69]).

${ }^{2}$ The taste-based discrimination, on the other hand, is developed by Becker (1957)[4]. In his book, he introduces the first economic model of discrimination. Becker's model assumes that employers have disamenity value to employing minority workers. In the beauty context, minority workers represent the unattractiveness workers. Employers may

\footnotetext{
2 Hamermesh 2012 finds that decision-makers are still more likely to respond to absolute rather than relative differences among physically attractive people.
} 
have unbiased beliefs about workers' performance but prefer hiring comparatively attractive people. Therefore, unattractive workers may have to accept a lower wage for identical productivity or, equivalently, be more productive given identical wage. Hamermesh \& Biddle (1994)[30] and Harper (2000)[34] both provide strong support for employer discrimination against unattractive or short workers.

Although the effect of attractiveness on earnings is shown to be attributed to employer discrimination, it is still difficult to determine whether employer discrimination is due to biased belief or distaste. The reason for this is that household survey data usually do not provide information regarding workers' job performance realization, employers' estimate of a worker's ability, and employers' reaction in wage adjustment if workers' true performance is observed. Fortunately, this difficulty can be overcome under experimental settings in which worker and employer's wage negotiation process can be observed as well as workers' task solving skill that is unrelated to physical attractiveness. Examples of laboratory experiments used to examine the beauty effect channels include Mobius and Rosenblat (2006)[58] and Deryugina and Shurchkov (2013a[15]). Both studies have found that employers' biased belief on the ability of attractive workers (through visual and oral stereotype) explains a large proportion of the beauty premium. Specifically, the latter one points out that the beauty premium can only be obtained from specific tasks (e.g. bargaining instead of data analysis or data entry). In the experiment, the authors repeat the wage bidding for several rounds and find that when the workers' true ability is revealed, the beauty premium completely vanishes due to the employers' quick learning process.

\subsection{Customer Discrimination/ Productivity}

It is possible that physically attractive workers are more productive than unattractive ones in some occupations, such as actors/ actress, sales assistant and waiters/ waitress etc. These types of occupations typically involve extensive interaction between workers and the customers. Therefore, such an advantage could arise from customer discrimination with customers preferring to interact with better-looking workers. Moreover, physical attractiveness may enhance workers' ability to engage in productive interaction with co- 
workers. Good working relationship with co-workers and the firm's clients can create a form of firm-specific human capital, which generates higher earnings for workers themselves and higher quasi-rents for their employers (Pfann et al., 2000[66]).

It is been shown that attractive salesmen generally enjoy the benefit from customer discrimination. Reingen and Kernan (1993)[68] suggest that buyers in the attractivesalesman condition are significantly more likely to grant a demonstration appointment and buy the product in a simulated buying-selling setting. Moreover, perceptions of attractiveness appear to induce buyers to behave more favorably toward attractive sellers. Using actual salespeople's data in shopping malls, Sachsida et al. (2003)[71] results point out that women with good appearance receive a reward of approximately 9 percent in their earnings and this reward is entirely induced by the productivity effect and not discrimination. Hamermesh and Biddle (1994)[30] and Biddle and Hamermesh (1998)[5] also examine whether productivity accounts for the beauty premium using household survey data and a sample of law school graduate data. However, their results only provide weak support for productivity-related discrimination. Hamermesh and Parker (2005)[32] continue to test this hypothesis using a sample of university instructors. Although they are able to uncover a positive association between standardized beauty scores and students' class ratings, they are still not able to disentangle the effect that stems from productivity difference from the one that stems from discrimination. Using an advertising industry sample, Pfann et al (2000)[66] show that executive's beauty raises firm's revenue, and the increase in firm's revenue far exceeds the extra wages that goodlooking executives obtained. Therefore, executives' beauty enhances firm's human capital and the wage premium obtained is primarily induced by productivity. In sum, the evidence provided from above suggests that productivity-related discrimination is highly occupational specific.

\subsection{Occupational Sorting}

It is reasonable to believe that one's physical attractiveness can help to determine the occupational choice that one makes as a worker. As it is been mentioned above the effect of attractiveness could be fairly large in occupations, which involve extensive interaction 
with customers (like sales assistants). However, one's occupational choice is not only based on the advantages that one believes he/ she has, but also on one's preferences regarding different activities and one's ability to perform different types of work. To put it differently, an individual does not choose to enter occupations solely based on one's appearance and the potential payoff to one's appearance in various occupations. The occupation decision also depends on individual characteristics other than appearance such as education level, past work experience, marital status, and parents' occupations etc. That is why attractive workers are observed in greater proportion in occupations in which attractiveness is rewarded, but not all individuals who work in occupations where beauty pays are attractive (and we find attractive people in occupations where beauty does not pay off). The fact that people see less variation in looks within an occupation than in the workforce as a whole is attributed to the fact that segregation in appearance is incomplete. On average, better-looking individuals choose occupations where looks are important, and below-average looking individuals avoid these types of occupations.

The occupational sorting channel has been investigated by several studies. Hamermesh and Biddle (1994)[30], Biddle and Hamermesh (1998)[5], Harper (2000)[34], and Doorley and Sierminska (2012)[18] all have found empirical support for the standard implication that workers who are well-endowed with beauty choose the type of occupations where the payoff to appearance is high. Liu (2014)[51] shows that more attractive women are more likely to participate in managerial/ administrative jobs while less likely to choose operative/ craftsmen jobs. In particular, Biddle and Hamermesh (1998)[5] extend the traditional sorting model to account for dynamic sorting of beauty using a longitudinal survey data. Using a sample of law school graduates, they first split the sample into individuals who work in private sector and public sectors five and fifteen years after graduation. They then investigate the sector-switching pattern based on attractiveness. Their results show that lawyers who left the private sector between year five and year fifteen are less attractive than those who stayed (controlling for other characteristics), while lawyers who switched from the public sector to private sector are more attractive than those who stayed. Their results provide evidence of dynamic sorting 
in directions consistent with changes in the relative returns to the individual characteristics.

\subsection{Beauty correlated with cognitive/ non-cognitive skill}

Another explanation for the existence of the beauty premium is that beauty may in fact be positively correlated with certain cognitive/ non-cognitive skills such as test score, communication skill, confidence, leadership skills, and personality etc., which are rewarded in the labor market or enable workers to enhance labor productivity (Feingold 1992)[20]. These cognitive/ non-cognitive skills are usually acquired during adolescent period through socialization or activities in high school. It is been shown that attractiveness at a younger age may contribute human capital investment during adolescence because good-looking children are given more attention by teachers and peer (Lerner et al., 1990[50]; Langlois et al., 2000[47]). An extensive body of research indicates the importance of cognitive/ non-cognitive skills obtained during high school in future labor market outcomes, such as test scores, college enrollment, social behavior, employment, occupational attainment, and wages (French et al 2009[23], Cobb-Clark \& Tan, 2011[12]; Carneiro et al., 2007[10]; Heckman \& Rubinstein, 2001[38]; Heckman et al., 2006[39]; Jacob, 2002[41]; Kuhn \& Weinberger, 2005[45]). Persico et al. (2004)[65] investigate the wage premium resulting from being tall. They point out that the height premium actually comes from teenage height instead of adult height. Being tall during adolescent period increases the likelihood of participation in high school sports and clubs. Participation in these activities promotes the acquisition of confidence, which in turn increases future wages. Mobius and Rosenblat (2006[58] and Scholz and Sicinski (2011)[72] reach similar conclusion using attractiveness measures. They find that more attractive individuals exude better communication skills, more confidence and more extroversion, which all translate into higher wages. Mocan and Tekin (2010)[59] evaluate the attractiveness effect on criminal activities and finds that unattractiveness increases a young adult's propensity for criminal activity. They argue that this is primary due to the fact that unattractiveness hinders student human capital development during high school. Han et al 2011[33] examine the direct and indirect effect of teenage body weight on adult wages and find that education is the main pathway for the indirect BMI wage penalty. 
They find that the BMI wage penalty is underestimated by about $18 \%$ for women and is not statistically significant for men.

Individual's cognitive skill such as test score and study performance may also be correlated with attractiveness. Von Bose (2012)[76] and Deryugina and Shurchkov (2013)[14] both show that physical attractive is positively correlated with high school GPA and university overall GPA. Others have shown that beauty and ability are complements at high levels of beauty, but substitutes at low levels (Fletcher 2009)[21].

\section{Empirical Estimation Methods}

The primary method used in the literature to model the beauty effect on labor market outcomes is a Mincer type human capital model or wage equation. This type of model regresses individual earnings (or log hourly wage) on categories of attractiveness (e.g. above-average and below-average), a set of productivity enhancing characteristics (e.g. years of schooling and potential experience etc.), and a vector of individual characteristics (e.g. race, marital status, union status, self-reported health status etc.). As it has been mentioned above, attractiveness may also be correlated with cognitive/ noncognitive skills. If these determinants are not controlled for, the estimated effect of attractiveness could be biased. Therefore, previous studies sometimes include IQ scores, high-school activities, and if the data allow the "big five" personality traits (openness, conscientiousness, extraversion, agreeableness, neuroticism). The coefficients on the attractiveness measure represent the marginal variation in wage in relation to beauty. Almost all the previous literature (including the psychological, sociology and economic literature) have adopted this type of linear model to construct baseline beauty effect estimates.

A less commonly used approach is introduced by Doorley and Sierminska (2012)[18], who use distribution regression followed by an Oaxaca-Blinder style decomposition (Oaxaca, 1973[63]; Blinder, 1973[7]). The primary reason to adopt this methodology is that the authors posit the effect of beauty may vary across the wage distribution. To proceed, they start by estimating the conditional distribution of wages in different attractiveness group (e.g. beautiful and plain) given individual characteristics. They then construct counterfactual wage distributions. The final wage differentials between 
beautiful and plain workers can be decomposed into the characteristics effect and the unexplained difference. The unexplained wage differentials are interpreted as the beauty premium/ plainness penalty.

One limitation of the Mincer type model and the distribution regression is that these methods do not allow for the potential channels to be separately identified. The empirical model proposed by Hamermesh and Biddle (1994)[30] solves the problem to some extent. They propose the following regression:

$w_{i}=\beta_{0}+\beta_{1} X_{i}+\beta_{2} \theta_{i}+\beta_{3} O C C_{i}+\beta_{4} \theta_{i} O C C_{i}+\varepsilon_{i}$

where $w_{i}$ represents log hourly earnings. $X_{i}$ is a vector of productivity-enhancing characteristics. $\theta_{\mathrm{i}}$ is a binary variable that equals to 1 if the worker is attractive and 0 otherwise. $\mathrm{OCC}_{\mathrm{i}}=1$ if the worker's occupation is as one where looks are productive. The $\varepsilon_{\mathrm{i}}$ are residuals. This regression nests a model of occupational sorting, employer discrimination as well as a productivity differential. The occupational sorting model implies $\beta_{3}>0$. The productivity/ customer discrimination model implies $\beta_{4}>0$ and $\beta_{2}=\beta_{3}=0$. The employer discrimination model implies $\beta_{2}>0$ and $\beta_{3}=\beta_{4}=0$. Examples of studies using the Hamermesh and Biddle (1994) model to examine the beauty effect channels include Harper (2000)[34], Sachsida et al. (2003)[71], Loureiro et al., (2011)[54], Doorley and Sierminska (2012)[18], and Johnston (2010) [42], etc.

Although the above model provides a convenient method to test the existence of potential transmission channels of the beauty effect, it is not without its caveat. One difficulty with using this model is to determine the set of occupations where looks are likely to enhance productivity. Clearly, there is no simple rule of thumb. In Hamermesh and Biddle (1994)[30], the authors use three different sources to identify these occupations. These sources include the Dictionary of Occupation Titles (DOT) (1977), three-point scale ratings on whether appearance might be important to a specific occupation by eight raters, and a survey conducted by Holzer (1993)[40]. According to their classification, the 
occupations in which attractiveness could possibly enhance productivity include sales occupations, cashiers, receptionists, and waitresses etc. These occupations evidently involve more interaction between workers and customers. Doorley and Sierminska (2012)[18] divide occupations into dressy and non-dressy taking advantage of a survey question asking individuals ' opinion on the importance of appearance in their professional life. In their dressy category, within which beauty may enhance workers' productivity, they identify occupations such as supervisors/ managers, intellectual professions, administrative employees, service, and sales employees etc. The occupations included in their dressy category are shown to be generally consistent with the original 1994 Hamermesh and Biddle paper.

Another difficulty in using this model is to disentangle the productivity channel from other sources. Although Hamermesh and Biddle (1994) are able to provide some support for productivity-related discrimination, the evidence is fairly weak. A related explanation, they provide, is that there are still inherent productivity differences that the data do not capture because of omitted variables. Due to this reason, alternative variations need to be incorporated to better identify this channel. One approach is to use data from workers who are from a relatively homogeneous group (a specific occupation). Biddle and Hamermesh (1998)[5] intend to overcome this difficulty by using a sample of graduates of a particular law school. To measure the wage differentials from consumer discrimination or productivity, they compare earnings between attorneys practicing in the private sector and those in the public sectors. The reasoning behind this research design is that, in the private sector, the duties of lawyers often include a marketing component in that they have to attract new clients and keep the existing ones. In public sectors, however, the ability to market one's services is not an essential part of the job. Therefore, the earning difference between private and public sectors also reveals customers' discrimination. In order to further separate the effect stemming from customers preferring to spend time with better-looking attorneys and away from the effect stemming from customers' belief that better-looking attorneys are more productive (obtain greater financial gains), the authors examine how mean attorneys attractiveness differ by legal specialization within the private sector. This test helps to determine whether attorneys' 
attractiveness can assist them in generating more favorable judgments from clients in each legal specialty. The results from these comparisons, however, only provide weak evidence for the belief that beauty produces more advantageous outcomes.

Even with the ability to estimate the impact of physical attractiveness on individual earnings, the literature still leaves open the question of how to separately identify productivity-related discrimination. Due to the fact that measures of productivity are fairly few and they are aggregated, given the heterogeneity of respondents' occupations in publicly available household survey, data on relatively homogeneous workers in specific occupation is definitely called for. The literature studying customer discrimination within occupation is still relatively thin, making this a valuable area for future research.

\section{Gender Differences}

The effect of attractiveness on labor market outcomes may vary with respect to gender. This is primarily due to the fact that attractiveness may result in different labor market opportunities for men and women. Although the participation gap has been narrowing, in general, women are still more likely than men to stay out of the labor force. This observation is particularly common for the1970s when women's stated goal was "career then family" (Goldin, 2004[26]). During the 1970s, about 65 percent of married women were in the labor force at age thirty (Goldin, 2004[26]), while overall about 97 percent of men were employed while only 57 percent of women were in the labor force (Liu, 2014[51]). What determines women's labor force participation decision apart from marital status, number of children and education? Beauty endowment may be one of these factors. As discussed in Section 3, it is possible that more attractive women will be able to gain more from a job than a less attractive counterpart. More attractive women may be more likely to work because beauty brings them more confidence (Mocan and Tekin, 2010[59]) and they may be more likely to take advantage of their attractiveness if it enhances their productivity at work. On the other hand, the disincentives associated with bad looks may lead women to avoid the labor market (Hamermesh, 2011[29]). Hamermesh and Biddle (1994)[30] investigate this point and show that married women 
with below-average looks are 3 to 11 percent less likely to participate in the labor market than above-average looking women. Harper (2000)[34] finds that the probability of unemployment falls from 2 percent to 0.9 percent for attractive women. Gehrsitz (2014)[25] finds that physically attractive men or women are more likely to work and be employed full-time than their average looking peers, but the effect is stronger for men. Borland and Leigh (2014)[8] suggest a relatively large negative effect (about 18 percentage points) of below-average beauty on women's probability of employment. Women's self-selection into the labor force based on beauty endowments alters the distribution of observed female beauty in the labor market. Since more attractive women are more likely to appear in the labor market and vise versa, one observes less female beauty variation and, therefore, a smaller beauty premium. However, selection based on beauty endowment is less prevalent for men given men's fairly high labor force participation rate, thus, one expects to observe larger beauty premium for men than for women.

Although women's self-selection explains the beauty premium gender differences, this explanation is only appropriate when women's labor force participation rate is low. From the 1970s to 2000s, married women's labor force participation continued to expand (Goldin, 2006[27]) and a narrowing of the participation gap between men and women has occurred (Goldin, 2014[28]). In 2012, the labor force participation rate for men between 15 to 54 years of age was about 89 percent, which is only 14 percent higher than that of their female counterpart (BLS, $2013^{3}$ ). Due to the converging roles of men and women in the labor market and at home over the past 40 years, the observed female beauty variation in the labor market should be largely expanded. Therefore, the beauty premium gap across genders is expected to decrease.

In the end, gender differences in the beauty premium/ penalty is an empirical issue. Careful studies on gender difference in the effects of attractiveness on earnings show that the above hypothesis is general true. By stacking two American and one Canadian dataset,

3 Title of the BLS article: Labor force projections to 2022: the labor force participation rate continues to fall. Article available at: http://www.bls.gov/opub/mlr/2013/article/labor-force-projections-to-2022-the-laborforce-participation-rate-continues-to-fall.htm 
Hamermesh and Biddle (1994) report that men who are assessed as being homely are penalized about 9 percent in hourly earnings while those who are viewed as having above-average looks receive an earning premium of 5 percent. Among women, there is a 4 percent attractiveness premium and a 5 percent plainness penalty in hourly earnings. Harper (2000)[34] shows that men who are rated as unattractive at both age 7 and 11 incur a large and significant pay penalty of 14.9 percent. This pattern also applies to their female counterpart with a 10.9 percent unattractiveness penalty. One point that needs to be noticed is that Harper (2000)[34] attractiveness measures are obtained from evaluating adolescents' appearances by their teachers. Since adolescents' appearance may change dramatically when people get older and may also contain relatively large measurement error, it is possible that the estimates suffer from attenuation bias. Borland and Leigh (2014)[8] show that, in the 1980s, above-average beauty for men is associated with a premium of 11.6 percent and below-average beauty with a penalty of 10.4 percent with the latter effect being statistically insignificant. For women, however, no statistically significant attractiveness premium or unattractiveness penalty is found. They conclude that over time (1984 and 2009) the returns to beauty from the effect on a worker's hourly wage are more or less constant. Mocan and Tekin (2010)[59] also confirm a similar pattern using a sample of young adults. Their results suggest that, using all three survey waves, the beauty premium is 4.5 percent for women, and being unattractive is associated with a 7 percent reduction in wages. The wage premium to be very attractive for men is 10.8 percent, and the penalty for being unattractive is the same amount as women (7 percent).

The above hypothesis regarding gender differences still holds even within specific occupations. Frieze et al. (1991)[24] investigates the attractiveness premium using a sample of 737 MBA graduates between 1973 and 1982. They first conduct a Chow Test to confirm that the salary relationships for men and women are different. They then estimate the beauty effect separately by gender. They find that more attractive men obtained higher starting salaries and continued to earn more over time. For women, however, there exists no effect of attractiveness on starting salaries although more attractive women begin to earn more with greater job experience. Biddle and Hamermesh 
(1998)[5] examine the payoff of law school graduates who graduated in the 1970s and 1980s. Their results indicate that the attractiveness effect of men is statistically significant five years after graduation with two standard deviation increases in attractiveness score associated with about a 10 percent increase in earnings. The estimated attractiveness effects for women, however, are indistinguishable from zero. Clearly, the measure of labor market outcomes may not be limited to individual earnings. Any measure that evaluates the performance in an occupation can be used as an outcome variable. In the case of university teaching, course/ instructor evaluations are reasonable measures of teaching performance. A number of studies have shown that better teaching evaluations increase teachers' salaries (Moore et al., 1998[60]; Kaun, 1983[43]). Therefore, teachers' attractiveness may have an indirect impact on their salary via students' class ratings. Hamermesh and Parker (2005)[32] evaluate beauty in the classroom. They find that a one standard deviation increase in the attractiveness score is associated with a 0.38-point increase in male teachers' class ratings while the beauty effect for female teachers is less than half compared to that of males.'

Although the (women's) self-selection hypothesis is generally supported by previous studies, it is not uncommon to see studies that reach different conclusions. French (2002)[22] is one such example. In this paper, the sample data used is collected from two worksites (a non-profit hospital and a large school district) in a Midwestern community in 1995-1997. Using self-reported appearance as a beauty measure, the author finds that women with above average appearance obtain about 8 percent higher earnings relative to women with an average appearance. There is no evidence that shows that women suffer from the plainness penalty. For men, neither the beauty premium nor the plainness penalty is detected in the regression results. Liu (2014)[51] find that gender differences in the beauty effect vary with the individual's age. The results suggest that men in their mid30s have no significant beauty premium. For women, on the other hand, a one standard deviation increase in the attractiveness rating is associated with a 5.4 percent increase in the hourly wage. At a later stage of the career (early-50s), men's attractiveness premium develops with one standard deviation increase in attractiveness score associated with 2.65 percent increase in hourly wage while women's attractiveness premium fades. However, 
their findings are consistent with the narrowing beauty premium gap hypothesis mentioned above.

The gender wage gap literature has indicated several sources of wage inequality across genders. These sources include workers' observed characteristics, gender-specific workforce composition change (Mulligan and Rubinstein, 2008[62][66]), collective bargaining effect (Blau and Kahn, 2003[6][67];Antonczyk et al, 2010[1][68]), competition (Weichselbaumer and Winter-Ebmer, 2007[77]), and work time flexibility (Goldin, 2014[28]). However, these studies do not consider the potential effect of physical attractiveness on individual earnings across genders. The literature reviewed in this section above confirms that gender differences in the beauty premium do exist and indicates that the role attractiveness plays in explaining the gender wage gap could be bigger than previously assumed.

\section{Country Findings}

It might be futile to search for a universal standard of beauty since they are determined within cultures (Hatfield \& Rapson, 2000[36]) and the variation of cultures around the world results in few consistent standards of beauty (Hatfield and Sprecher, 1986[37]). One question one may want to ask is whether people in different culture all favor beauty? Is the beauty premium/ plainness penalty consistent across different countries? In order to answer this question, we compare findings from previous international studies. The comparisons are shown in Table 1. 
Table 1: Comparison of the Effect of Beauty on Wages across Various Countries

\begin{tabular}{|c|c|c|c|c|c|c|}
\hline \multirow[b]{2}{*}{ Country } & \multirow[b]{2}{*}{ Paper } & \multirow[b]{2}{*}{ Gender } & \multirow[b]{2}{*}{ Occupation } & \multicolumn{2}{|c|}{ Wage Effect } & \multirow[b]{2}{*}{ Notes } \\
\hline & & & & $\begin{array}{c}\text { Above-Average } \\
\text { Looks (\%) }\end{array}$ & $\begin{array}{c}\text { Below-Average } \\
\text { Looks (\%) }\end{array}$ & \\
\hline \multirow{4}{*}{ Canada \& U.S. } & Hamermesh \& Biddle & Men & & 5.4 & -8.9 & \multirow{9}{*}{ stacked estimates } \\
\hline & $(1994)$ & & General & & & \\
\hline & & Women & & 3.9 & -5.5 & \\
\hline & & Men & & 10.8 & -7 & \\
\hline U.S. & Mocan \& Tekin (2010) & & General & & & \\
\hline \multirow{4}{*}{ United Kingdom } & & Women & & 4.5 & -7 & \\
\hline & \multirow{3}{*}{ Harper (2000) } & Men & & not significant & -14.9 & \\
\hline & & \multirow{2}{*}{\multicolumn{2}{|c|}{ General }} & & & \\
\hline & & & & not significant & -10.9 & \\
\hline Netherland & Pfann et al. (2000) & Both & Advertising Firm & $\begin{array}{l}18800 \text { DFL inc } \\
\text { average beauty cha } \\
\text { percentile (assun } \\
\text { wages averaging }\end{array}$ & $\begin{array}{l}\text { se in wage with } \\
\text { es from } 10 \text { th to } 90 \text { th } \\
\text { a } 7.5 \% \text { effect on } \\
000 \text { DFL per year) }\end{array}$ & $\begin{array}{l}\text { wage effect } \\
\text { inferred from } \\
\text { extraneous } \\
\text { estimates }\end{array}$ \\
\hline \multirow{3}{*}{ China (Shanghai) } & \multirow{4}{*}{ Hamermesh et al. (2002) } & Men & \multirow{4}{*}{ General } & - & - & \\
\hline & & & & & & \\
\hline & & Women & & 17.9 & - & \\
\hline \multirow{3}{*}{ Brazil } & & Men & & not significant & not significant & \\
\hline & Sachsida et al. (2003) & \multirow{2}{*}{\multicolumn{2}{|c|}{ Salesmen }} & & & \\
\hline & & & & 9 & not significant & \\
\hline \multirow{2}{*}{ Germany } & Doorley \& Sierminska & Men & & 14 & - & \\
\hline & $(2012)$ & \multicolumn{2}{|r|}{ General } & 20 & - & \\
\hline \multirow{4}{*}{ Luxembourg } & Doorley \& Sierminska & Men & \multirow{3}{*}{ General } & -3 & - & \\
\hline & $(2012)$ & & & & & \\
\hline & & Women & & 10 & - & \\
\hline & & Men & \multirow{4}{*}{ General } & 11.6 & not significant & \\
\hline \multirow[t]{3}{*}{ Australia in 1984} & Borland and Leigh (2014) & & & & & \\
\hline & & Women & & not significant & not significant & \\
\hline & & Men & & not significant & -12.9 & \\
\hline \multirow[t]{2}{*}{ Australia in 2009} & Borland and Leigh (2014) & & \multirow[t]{2}{*}{ General } & & & \\
\hline & & Women & & not significant & not significant & \\
\hline
\end{tabular}


Evidently, physical attractiveness is rewarded in almost all country findings, except for men in Luxembourg. Among all the countries listed, the beauty premium in Germany and China are the highest (from 17.9 percent to 20 percent), especially for women. The largest plainness penalty shows up in studies investigating British and Australian data (from -10.9 percent to -14.9 percent). Interestingly, Harper (2000)[34] and Borland and Leigh (2014)[8] estimates show that individuals in the United Kingdom and women in Australia do not receive any attractiveness premium. This similarity in the payoff of attractiveness may be due to the similarity in the historical economic structure, as well as culture in both countries. The reader should notice that Table 1 presents selected country findings from the literature. Some studies that investigate the beauty premium have adopted either an alternative attractiveness measures (e.g. height, weight, and hair color etc.) or used alternative labor market outcomes (e.g. whether individual gets called back during hiring process). Ruffle and Shtudiner (2010)[70] and Lopez Boo et al (2013)[53] are examples of this kind of research. Both papers examine the link between beauty and hiring practices but use sample from different countries. Ruffle and Shtudiner (2010) investigates data from Israel while Lopez Boo et al. (2013)[53] looks at data from Buenos Aires, Argentina. Both studies provide evidence that attractive people receive more responses (callbacks) from employers than unattractive people. Also, the attractive ones tend to receive callbacks sooner than their unattractive counterparts. ${ }^{4}$

\section{Conclusion}

The attention given to beauty-based discrimination has increased in recent years. As this review has shown, most previous studies in this area focus on estimating the magnitude of the effect of physical attractiveness on labor market outcomes and trying to identify channels through which attractiveness can affect these outcomes using various survey data sources. This body of literature generally confirms the existence of a positive association between physical attractiveness and various labor market outcomes such as individual earnings and employment opportunity (call-back rate). Moreover, several explanations (e.g. employer discrimination, customer discrimination/ productivity, and occupational sorting etc.) of how beauty affects labor market outcomes are provided.

4 An interesting discussion on the possible way to reduce unfair advantages related to physical appearance can be found in Krause et al 2012[44]. 
As it is mentioned above, all explanations are supported by previous studies to some extent; the empirical evidence in support of some of the potential explanations is still relative thin. This is particularly true for the productivity channel. Therefore, researchers could contribute in this area by using within occupation specific data, where workers can be viewed as relatively homogeneous. Additionally, this would partly remove the unobserved factors of productivity.

Another area where researchers could help shed light is the endogeneity of beauty. In previous studies, physical attractiveness is generally treated as exogenously determined. However, perceived attractiveness may be correlated with clothing/ cosmetics spending, plastic surgery, and parents' attractiveness; these are usually not observed from survey data. There is only a small body of literature that considers this explicitly (e.g. Lee and Ryu, 2012[49]; Hamermesh et al 2002[31]). Failing to consider the endogeneity issue may cause the estimated beauty effect to be biased upward.

\section{Reference:}

[1] Dirk Antonczyk, Bernd Fitzenberger, and Katrin Sommerfeld. Rising wage inequality, the decline of collective bargaining, and the gender wage gap. Labour Economics, 17(5):835-847, 2010.

[2] Susan Averett and Sanders Korenman. The Economic Reality of the Beauty Myth. Journal of Human Resources, 31(2):304-330, 1996.

[3] Robert Barro. So You Want to Hire the Beautiful. Well, Why Not? Business Week, 03/16/1998 1998.

[4] Gary S. Becker. The Economics of Discrimination. University of Chicago Press Economics Books. University of Chicago Press, May 1971.

[5] Jeff E Biddle and Daniel S Hamermesh. Beauty, Productivity, and Discrimination: Lawyers’ Looks and Lucre. Journal of Labor Economics, 16(1):172-201, January 1998.

[6] Francine D. Blau and Lawrence M. Kahn. Understanding International Differences in the Gender Pay Gap. Journal of Labor Economics, 21(1):106-144, January 2003. 
[7] Alan S. Blinder. Wage discrimination: Reduced form and structural estimates. The Journal of Human Resources, 8(4):pp. 436-455, 1973.

[8] Jeff Borland and Andrew Leigh. Unpacking the beauty premium: What channels does it operate through, and has it changed over time? Economic Record, 90 (288):17-32, March 2014.

[9] Marco Caliendo and Markus Gehrsitz. Obesity and the Labor Market: A Fresh Look at the Weight Penalty. IZA Discussion Papers 7947, Institute for the Study of Labor (IZA), February 2014.

[10] Pedro Carneiro, Claire Crawford, and Alissa Goodman. The impact of early cognitive and non-cognitive skills on later outcomes. 2007.

[11] John Cawley. The impact of obesity on wages. Journal of Human Resources, 39(2):451-474, 2004.

[12] Deborah A Cobb-Clark and Michelle Tan. Noncognitive skills, occupational attainment, and relative wages. Labour Economics, 18(1):1-13, 2011.

[13] Angus Deaton and Raksha Arora. Life at the top: the benefits of height. Economics and Human Biology, 7(2):133-136, 2009.

[14] Tatyana Deryugina and Olga Shurchkov. Does Beauty Matter in Undergraduate Education? MPRA Paper 53582, University Library of Munich, Germany, August 2013. [15] Tatyana Deryugina and Olga Shurchkov. When are appearances deceiving? The nature and evolution of the beauty premium. May 2013.

[16] Karen Dion, Ellen Berscheid, and Elaine Walster. What is beautiful is good. Journal of personality and social psychology, 24(3):285, 1972.

[17] Robert L Dipboye, Richard D Arvey, and David E Terpstra. Sex and physical attractiveness of raters and applicants as determinants of resumé evaluations. Journal of Applied Psychology, 62(3):288, 1977.

[18] Karina Doorley and Eva Sierminska. Myth or Fact? The Beauty Premium across the Wage Distribution. IZA Discussion Papers 6674, Institute for the Study of Labor (IZA), June 2012.

[19] Karina Doorley and Eva Sierminska. First impressions count, but can personality affect wages? Technical report, March 2014. 
[20] Alan Feingold. Good-looking people are not what we think. Psychological Bulletin, 111(2):304-41, 1992.

[21] Jason M. Fletcher. Beauty vs. brains: Early labor market outcomes of high school graduates. Economics Letters, 105(3):321-325, December 2009.

[22] Michael T French. Physical appearance and earnings: further evidence. Applied Economics, 34:569-572, 2002.

[23] Michael T. French, Philip K. Robins, Jenny F. Homer, and Lauren M. Tapsell. Effects of physical attractiveness, personality, and grooming on academic performance in high school. Labour Economics, 16(4):373-382, August 2009.

[24] Irene Hanson Frieze, Josephine E Olson, and June Russell. Attractiveness and income for men and women in management. Journal of Applied Social Psychology, 21(13):1039-1057, 1991.

[25] Markus Gehrsitz. Looks and Labor: Do Attractive People work more? Labour, 28(3):269-287, 2014.

[26] Claudia Goldin. The long road to the fast track: Career and family. The Annals of the American Academy of Political and Social Science, 596(1):20-35, 2004.

[27] Claudia Goldin. The quiet revolution that transformed women's employment, education, and family. American Economic Review, 96(2):1-21, May 2006.

[28] Claudia Goldin. A Grand Gender Convergence: Its Last Chapter. American Economic Review, 104(4):1091-1119, April 2014.

[29] Daniel S Hamermesh. Beauty pays: Why attractive people are more successful. Princeton University Press, 2011.

[30] Daniel S Hamermesh and Jeff E Biddle. Beauty and the labor market. American Economic Review, 84(5):1174-94, December 1994.

[31] Daniel S. Hamermesh, Xin Meng, and Junsen Zhang. Dress for success-does primping pay? Labour Economics, 9(3):361-373, July 2002.

[32] Daniel S Hamermesh and Amy Parker. Beauty in the classroom: Instructors’ pulchritude and putative pedagogical productivity. Economics of Education Review, 24(4):369-376, 2005.

[33] Euna Han, Edward C. Norton, and Lisa M. Powell. Direct and indirect effects of body weight on adult wages. Economics \& Human Biology, 9(4):381 - 392, 2011. 
[34] Barry Harper. Beauty, stature and the labour market: a British cohort study. Oxford Bulletin of Economics and Statistics, 62:771-800, 2000.

[35] Katherine M Haskins and H Edward Ransford. The relationship between weight and career payoffs among women. In Sociological Forum, volume 14, pages 295-318. Springer, 1999.

[36] E. Hatfield and R. L. Rapson. Physical attractiveness, volume 3. John Wiley \& Sons, 2000.

[37] Elaine Hatfield and Susan Sprecher. Mirror, mirror. 1986.

[38] James J Heckman and Yona Rubinstein. The importance of noncognitive skills: Lessons from the GED testing program. American Economic Review, pages 145-149, 2001.

[39] James J Heckman, Jora Stixrud, and Sergio Urzua. The effects of cognitive and noncognitive abilities on labor market outcomes and social behavior. Journal of Labor Economics, 24(3):411-482, 2006.

[40] Harry Holzer. Multi-city study of urban inequality. Unpublished manuscript, Michigan State University, 1993.

[41] Brian A Jacob. Where the boys aren't: non-cognitive skills, returns to school and the gender gap in higher education. Economics of Education Review, 21(6):589-598, 2002.

[42] David W Johnston. Physical appearance and wages: Do blondes have more fun? Economics Letters, 108(1):10-12, 2010.

[43] David E Kaun. Faculty advancement in a nontraditional university environment. Industrial and Labor Relations Review, 37:592, 1983.

[44] Annabelle Krause, Ulf Rinne, and Klaus F. Zimmermann. Anonymous job applications in Europe. IZA Journal of European Labor Studies, 1(5), 2012.

[45] Peter Kuhn and Catherine Weinberger. Leadership skills and wages. Journal of Labor Economics, 23(3):395-436, 2005.

[46] S Lambert. Reactions to a stranger as a function of style of dress. Perceptual and Motor Skills, 35(3):711-712, 1972. 
[47] Judith H Langlois, Lisa Kalakanis, Adam J Rubenstein, Andrea Larson, Monica Hallam, and Monica Smoot. Maxims or myths of beauty? A meta-analytic and theoretical review. Psychological Bulletin, 126(3):390, 2000.

[48] Judith Candib Larkin and Harvey A Pines. No Fat Persons Need Apply Experimental Studies of the Overweight Stereotype and Hiring Preference. Work and Occupations, 6(3):312-327, 1979.

[49] S. Lee and K. Ryu. Plastic Surgery: Investment in Humna Capital or Consumption? Journal of Human Capital, 6(3):224-250, 2012.

[50] Richard M Lerner, Mary Delaney, Laura E Hess, Jasna Jovanovic, and Alexander Von Eye. Early adolescent physical attractiveness and academic competence. The Journal of Early Adolescence, 10(1):4-20, 1990.

[51] Xing Liu. Physical attractiveness and earnings: evidence from a longitudinal survey. Technical report, Working paper, University of Arizona, 2014.

[52] Eng Seng Loh. The economic-effects of physical appearance. Social Science Quarterly, 74(2):420-438, 1993.

[53] Florencia López Bóo, Martn A Rossi, and Sergio S Urzua. The labor market return to an attractive face: Evidence from a field experiment. Économics Letters, 118(1):170-172, 2013.

[54] Paulo Loureiro, Adolfo Sachsida, and Mario Cardoso Mendonca. Links between physical appearance and wage discrimination: Further evidence. International Review of Social Sciences and Humanities, 1(2):1-16, Feb 2012.

[55] Stan Malos. Appearance-based sex discrimination and stereotyping in the workplace: Whose conduct should we regulate? Employee Responsibilities and Rights Journal, 19(2):95-111, 2007.

[56] Cheryl L Maranto and Ann Fraedrich Stenoien. Weight discrimination: a multidisciplinary analysis. Employee Responsibilities and Rights Journal, 12(1):9-24, 2000.

[57] Carol T Miller. Categorization and the physical attractiveness stereotype. Social Cognition, 6(3):231-251, 1988.

[58] Markus M Mobius and Tanya S Rosenblat. Why beauty matters. The American Economic Review, pages 222-235, 2006. 
[59] Naci Mocan and Erdal Tekin. Ugly criminals. The Review of Economics and Statistics, 92(1):15-30, 2010.

[60] William J Moore, Robert J Newman, and Geoffrey K Turnbull. Do academic salaries decline with seniority? Journal of Labor Economics, 16(2):352-366, 1998.

[61] Paula C Morrow. Physical attractiveness and selection decision making. Journal of Management, 16(1):45-60, 1990.

[62] Casey B Mulligan and Yona Rubinstein. Selection, investment, and women's relative wages over time. The Quarterly Journal of Economics, 123(3):1061-1110, 2008.

[63] Ronald Oaxaca. Male-female wage differentials in urban labor markets. International Economic Review, 14(3):693-709, October 1973.

[64] Gordon L. Patzer, editor. The Physical Attractiveness Phenomena. New York: Plenum Press, 1985.

[65] Nicola Persico, Andrew Postlewaite, and Dan Silverman. The Effect of Adolescent Experience on Labor Market Outcomes: The Case of Height. Journal of Political Economy, 112(5):1019-1053, October 2004.

[66] Gerard A Pfann, Jeff E Biddle, Daniel S Hamermesh, and Ciska M Bosman. Business success and businesses' beauty capital. Economics Letters, 67(2):201-207, 2000.

[67] Charles A Register and Donald R Williams. Wage effects of obesity among young workers. Social Science Quarterly, 71(1):130-141, 1990.

[68] Peter H Reingen and Jerome B Kernan. Social perception and interpersonal influence: Some consequences of the physical attractiveness stereotype in a personal selling setting. Journal of Consumer Psychology, 2(1):25-38, 1993.

[69] Ronald E Riggio and Barbara Throckmorton. The relative effects of verbal and nonverbal behavior, appearance, and social skills on evaluations made in hiring interviews. Journal of Applied Social Psychology, 18(4):331-348, 1988.

[70] Bradley Ruffle and Ze'ev Shtudiner. Are good-looking people more employable? Ben-Gurion University of the Negev. Discussion Paper, (10-06), 2010.

[71] Adolfo Sachsida, Adriana Cristina Dornelles, and Carlos Wagner Mesquita. Beauty and the labor market-study one specific occupation. Available at SSRN 505742, 2003. 
[72] John Karl Scholz and Kamil Sicinski. Facial attractiveness and lifetime earnings: Evidence from a cohort study. Review of Economics and Statistics, 2014.

[73] Mark Snyder. When belief creates reality. Advances in Experimental Social Psychology, 18:247-305, 1984.

[74] Richard H Steckel. Stature and the standard of living. Journal of Economic Literature, pages 1903-1940, 1995.

[75] Debra Umberson and Michael Hughes. The impact of physical attractiveness on achievement and psychological well-being. Social Psychology Quarterly, 1987.

[76] Caroline von Bose. Child stars vs. ugly ducklings: Does adolescent attractiveness contribute to the beauty premium? Technical report, Working paper, 2012.

[77] Doris Weichselbaumer and Rudolf Winter-Ebmer. The effects of competition and equal treatment laws on gender wage differentials. Economic Policy, 22(50):235-287, 2007. 